динамики реальных располагаемых денежных доходов населения, рассчитанных с учетом изменения индекса потребительских цен за рассматриваемый период.

$$
* * *
$$

1. Статистика: учебное пособие / под ред. доктора экономических наук, профессора, заслуженного работника высшей школы РФ И.М. Суркова. - Воронеж, изд-во ФГБОУ ВО Воронежский ГАУ, 2017. $-243 \mathrm{c}$

2. Зотова А.А. Факторы, влияющие на заработную плату / А.А. Зотова, В.В. Малашенко, Е.Б. Панина // Управление инновационным развитием агропродовольственных систем на национальном и региональном уровнях: Материалы международной научно-практической конференции, 13-14 июня 2019 г., ФГБОУ ВО Воронежский ГАУ - ФГБНУ НИИЭОАПК ЦЧР России; в 2-х частях. Ч. ІІ. - Воронеж: ФГБОУ ВО Воронежский ГАУ, 2019. - С. 139 - 143.

3. Медведева А.Н. Анализ и оценка эффективности использования трудового потенциала в аграрной сфере Воронежской области // А.Н. Медведева, Е.Б. Панина // Молодежный вектор развития молодежной науки: материалы 71-й студенческой научной конференции. - Ч. III - Воронеж: ФГБОУ ВО Воронежский ГАУ, 2020. - С. 292 - 298.

4. Калабина Е.С. Статистическое исследование денежных доходов населения Воронежской области / Е.С. Калабина, Ю.А. Прокопова, С.И. Панин // Молодежный вектор развития молодежной науки: материалы 69-й студенческой научной конференции. - Ч. V. - Воронеж: ФГБОУ ВО Воронежский ГАУ, 2018. - С. $134-139$.

5. Статистика: учебник для вузов / И.И. Елисеева [и др.]; под ред. И.И. Елисеевой. - М.: Проспект, 2020. - 444 c.

6. Официальный сайт территориального органа Федеральной службы государственной статистики по Воронежской области: https://voronezhstat.gks.ru

\title{
Экономический анализ эффективности производства зерна на примере предприятий Воронежской области
}

Воронежский государственный аграрный университет имени императора Петра I

(Россия, Воронеж)

doi: $10.18411 / 1 j-07-2021-49$

\section{Аннотация}

В статье рассматривается анализ влияния различных факторов на эффективность производства зерна на предприятиях воронежской области и подходы к увеличению их рентабельности.

Ключевые слова: рентабельности производства, показатели, производство зерна.

\section{Abstract}

The article deals with the analysis of the influence of various factors on the efficiency of grain production at enterprises of the Voronezh region and approaches to increasing their profitability.

Keywords: profitability of production, indicators, grain production.

Решающее значение для увлечения всех отраслей сельского хозяйства имеет наращивание производства зерна. Зерновое хозяйство составляет основы растениеводства и всего сельскохозяйственного производства. Это определяется многосторонними связями зернового производства с определёнными отраслями сельского хозяйства и промышленности.

Вопрос производства зерна в нашей стране является важным, так как зернопродукты формируют $45 \%$ продовольственного рынка и дают $60 \%$ всего 
потребляемого населением белка и 70\% углеводов. Удельный вес которых в структуре посевных площадей составляет почти $60 \%$.

В 2020 году общий объем посевных площадей под растениеводческие культуры уменьшился на 250 тыс. га $0,3 \%$ по сравнению с предыдущим годом. В структуре всех посевных площадей России зерновые и зернобобовые культуры в 2020 году увеличились на 1321 тыс. га по сравнению с 2019 годом.

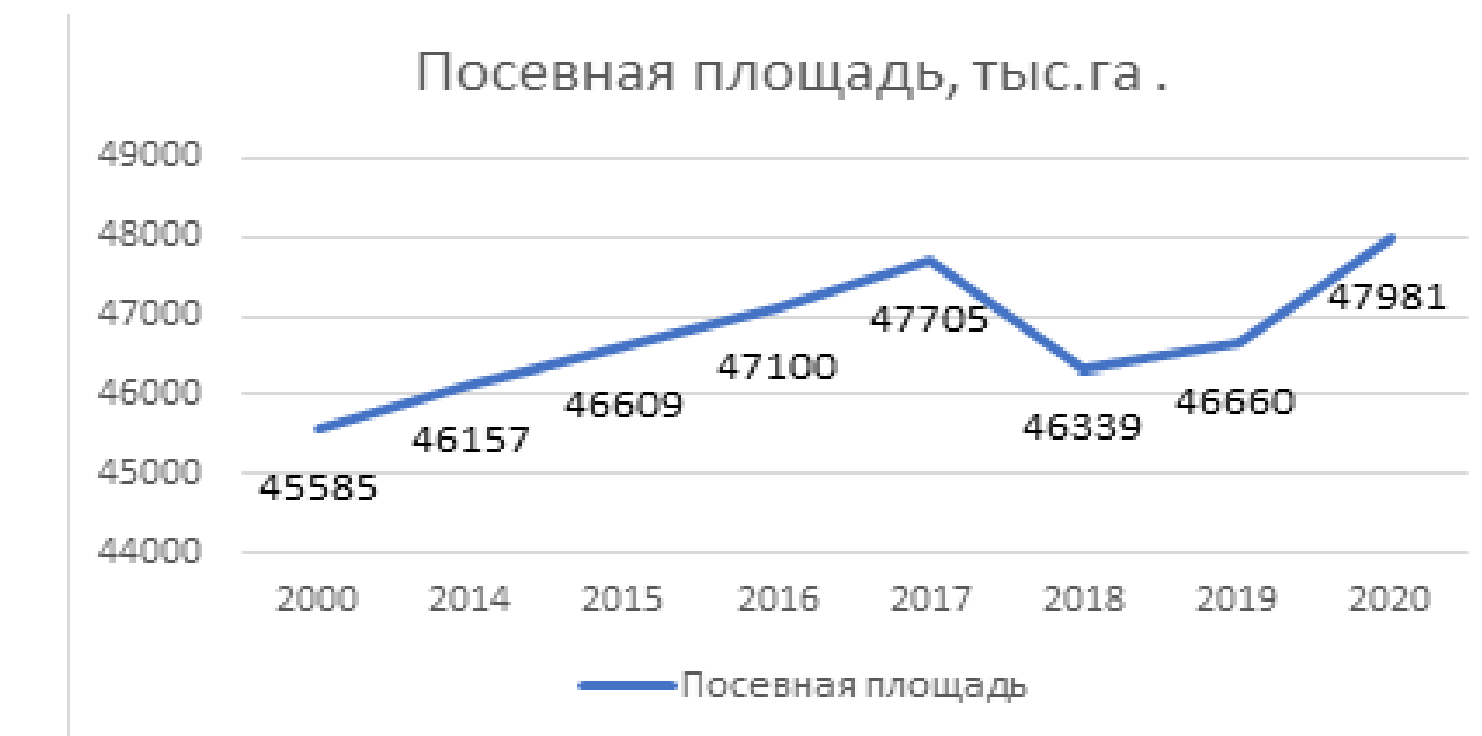

Рисунок 1 - Динамика посевных площадей зерновых культур, тыс. га в период с 2000 по 2020 годы в России.

Также, В 2019 - 2020 гг. наблюдается прирост площади посевных площадей не только под пшеницу, но и под рожь, просо, кукурузу и другие. В 2020 году в большей степени были расширены посевные площади под рожь, которые увеличились на 127 тыс. га (16,2\%), а также под просо - на 58 тыс. га $(14,8 \%)$ и кукурузу - на 279 тыс. га (10,8\%). Однако, несмотря на расширения посевных площадей некоторых зерновых культур в 2020 году, наблюдается также их сокращение в отношении, в первую очередь, тритикале - на 26 тыс. га (18,4\%). Уменьшение посевных площадей коснулось также сорго - 3 тыс. га (-3,5\%), ячменя - 261 тыс. га (-3\%) и овса - 65 тыс. га $(-2,6 \%)$. Рассмотрим это наглядно на графике.

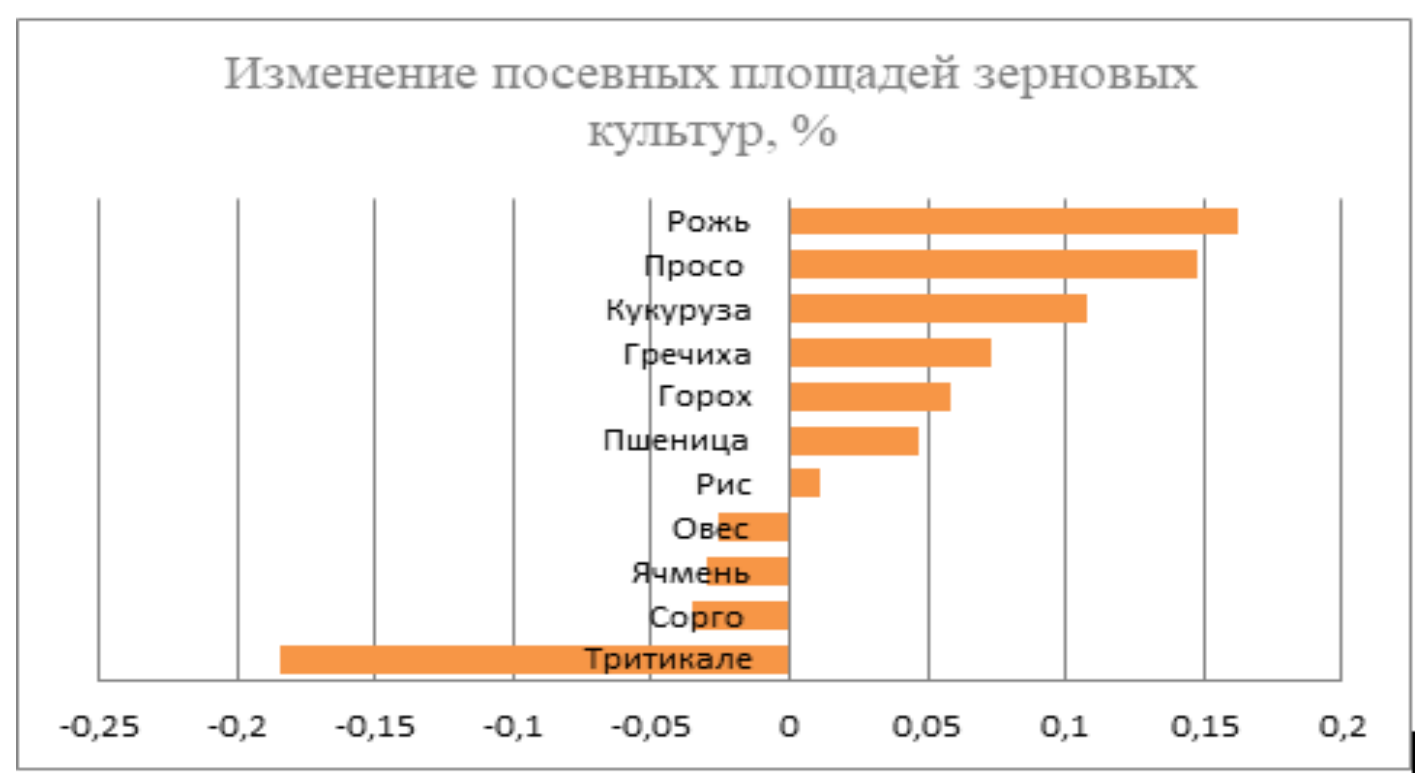

Рисунок 2 - Изменение посевных площадей зерновых культур в 2020 г. по отношению к 2019 г., \% 
Для полного описания состояния производства зерна по Воронежской области за последние 7 лет, рассмотрим и представим данные в таблице 1.

Таблица 1

Показатели производства зерна по Воронежской области за 2013-2019 г2.

\begin{tabular}{|l|c|c|c|c|c|c|c|c|}
\hline \multicolumn{1}{|c|}{ Показатели } & 2013 & 2014 & 2015 & 2016 & 2017 & 2018 & 2019 & $\begin{array}{c}\text { Темп } \\
\text { при- } \\
\text { роста, \% }\end{array}$ \\
\hline $\begin{array}{l}\text { 1.Валовый сбор } \\
\text { зерна,ц }\end{array}$ & $\begin{array}{c}21892 \\
476\end{array}$ & $\begin{array}{c}27022 \\
574\end{array}$ & $\begin{array}{c}23383 \\
428\end{array}$ & $\begin{array}{c}28928 \\
185\end{array}$ & $\begin{array}{c}39588 \\
293.3\end{array}$ & $\begin{array}{c}36125 \\
816.6\end{array}$ & $\begin{array}{c}39576 \\
654.6\end{array}$ & 80.78 \\
\hline $\begin{array}{l}2 . \text { Посевная } \\
\text { площадь, га }\end{array}$ & 886304 & 839410 & $\begin{array}{c}905 \\
896\end{array}$ & $\begin{array}{c}892 \\
355.1\end{array}$ & $\begin{array}{c}100 \\
9116.6\end{array}$ & $\begin{array}{c}105 \\
6206\end{array}$ & $\begin{array}{c}111 \\
1569.4\end{array}$ & 24.99 \\
\hline $\begin{array}{l}\text { 3.Урожайность, } \\
\text { ц/га }\end{array}$ & 24.7 & 32.2 & 25.8 & 32.4 & 39.2 & 34.2 & 35.6 & 44.13 \\
\hline $\begin{array}{l}\text { 4.Себестои- } \\
\text { мость 1 ц., руб. }\end{array}$ & 519.63 & 444.21 & 615.89 & 590.27 & 534.33 & 676.38 & 673.37 & 29.59 \\
\hline $\begin{array}{l}\text { 5.Ценареализа- } \\
\text { ции 1 ц. зерна, } \\
\text { руб. }\end{array}$ & 552.7 & 609.42 & 819.7 & 808.14 & 653.01 & 877.73 & 954.58 & 72.71 \\
\hline $\begin{array}{l}\text { 6. Уровень } \\
\text { рентабельности } \\
\text { производста } \\
\text { зерновых, \% }\end{array}$ & 6.36 & 37.19 & 33.09 & 36.91 & 22.21 & 29.77 & 41.76 & \\
\hline
\end{tabular}

Таким образом, можно сделать вывод, что темпы прироста уровня цены реализации значительно превышают темпы прироста себестоимости. Также следует отметить, что темпы прироста урожайности растут, как темпы прироста посевной площади и валового сбора. Кроме того, уровень рентабельности производства в 2019 году увеличился на $35.4 \%$ по сравнению с 2013.

Для определения эффективности производства зерна мы провели анализ рентабельности и прибыли производства зерна, который проводили на примере Калачевского, Аннинского и Семилукского районов Воронежской области. Нами был использован метод статистической группировки, засчет которого стало возможным наблюдать за взаимосвязью признаков общественных явлений. В нашем случае, группировочным признаком является цена реализации зерновых культур по хозяйствам Калачевского, Аннинского и Семилукского районов Воронежской области. В подтверждение полученным данным аналитической группировки мы выявили, что чем выше цена реализации зерновых культур, тем выше уровень рентабельности зерновых культур. В первой группе при минимальной цене реализации зерновых культур 774.5 руб. уровень рентабельности составил $56.19 \%$, тогда как в третьей группе при максимальной цене реализации 1277.1 руб. уровень рентабельности составляет $143.8 \%$. Следовательно, третья группа стала рентабельна. В ходе исследования выяснилось, что основными факторами, влияющими на прибыль и рентабельность являются:

1. Количество реализованной продукции.

2. Себестоимость 1 ц. реализованной продукции.

3. Цена реализации 1 ц. продукции.

Далее нами была разработана многофакторная экономико-математическая модель. В модель были заложены следующие факторы:

Ү-Уровень рентабельности зерна, \%

$\mathrm{X}_{1}$-Урожайность зерна, ц/га.

$\mathrm{X}_{2}$-Трудоемкость 1 ц. зерна, чел-час.

$\mathrm{X}_{3}$-Себестоимость 1 ц. реализованного зерна, руб.

$\mathrm{X}_{4}$-Уровень интенсивности, руб. 
$\mathrm{X}_{5}$-Уровень специализации, \%

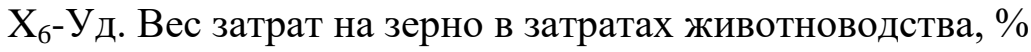

$\mathrm{X}_{7}$-Количество реализованного зерна, ц.

$\mathrm{X}_{8}$-Цена 1 ц. реализованного зерна, руб.

В результате путем пошагового решения была получена многофакторная корреляционно-регрессионная модель уровня рентабельности зерна по анализируемым предприятиям.

Таблиия 2

Многофакторная экономико-математическая модель уровня рентабельности зерна

\begin{tabular}{|c|c|c|c|c|c|c|c|c|}
\hline & $\begin{array}{l}\text { Коэффри } \\
\text { циенты }\end{array}$ & $\begin{array}{l}\text { Станда } \\
\text { ртная } \\
\text { ошибка }\end{array}$ & $\begin{array}{c}t- \\
\text { cmamuc } \\
\text { тика }\end{array}$ & $\begin{array}{c}P- \\
\text { Значени } \\
e\end{array}$ & $\begin{array}{c}\text { Нижние } \\
95 \%\end{array}$ & $\begin{array}{c}\text { Верхние } \\
95 \%\end{array}$ & $\begin{array}{l}\text { Нижни } \\
\text { е } 95.0 \%\end{array}$ & $\begin{array}{c}\text { Верхние } \\
95.0 \%\end{array}$ \\
\hline Y-пересечение & -59.3682 & 31.38015 & -1.8919 & 0.075664 & -125.575 & 6.838094 & -125.57 & 6.838094 \\
\hline $\begin{array}{c}\text { Количество } \\
\text { реализованного } \\
\text { зерна }(x 7)\end{array}$ & -0.00078 & 0.000353 & -2.19856 & 0.042043 & -0.00152 & $-3.1 E-05$ & -0.0015 & $-3.1 E-05$ \\
\hline $\begin{array}{c}\text { Себестоимость } 1 \\
\text { и реализованного } \\
\text { зерна, руб (хз) }\end{array}$ & -0.0327 & 0.00841 & -3.88783 & 0.001183 & -0.05044 & -0.01495 & -0.0504 & -0.01495 \\
\hline $\begin{array}{c}\text { Цена } 1 \text { и } \\
\text { реализованного }\end{array}$ & 0.120098 & 0.032819 & 3.659355 & 0.001942 & 0.050855 & 0.189341 & 0.05086 & 0.189341 \\
\hline
\end{tabular}

Анализируя полученную многофакторную экономико-математическую модель, мы видим, что при повышении себестоимости 1 ц реализованного зерна на 1 руб. уровень рентабельности будет снижаться на $3.3 \%$, в то же время при повышении цены 1 ц реализованного зерна на 1 руб. уровень рентабельности увеличится на $12 \%$.

Математическое уравнение регрессии выглядит следующим образом:

$\mathrm{Y}\left(\mathrm{x}_{2}, \mathrm{x}_{3}, \mathrm{x}_{8}\right)=-59.37-1,0008 \mathrm{x}_{2}-0,032 \mathrm{x}_{3}+0,12 \mathrm{x}_{8}$

Таблица 3

Регрессионная статистика.

\begin{tabular}{|c|c|}
\hline $\begin{array}{c}\text { Наименование } \\
\text { R }\end{array}$ & Показатели \\
\hline $\begin{array}{c}\text { Rнженвадрат } \\
\text { R-квай }\end{array}$ & 0.827993544 \\
\hline $\begin{array}{c}\text { Нормированный } \\
\text { R-квадрат }\end{array}$ & 0.630086245 \\
\hline $\begin{array}{c}\text { Стандартная } \\
\text { ошибка }\end{array}$ & 17.40285587 \\
\hline Наблюдения & 21 \\
\hline
\end{tabular}

Проанализировав таблицу 3, мы можем сделать вывод о том, что между факторами и уровнем рентабельности прямая и очень высокая (поскольку коэффициент корреляции равен 0,83). Коэффициент детерминации $\left(\mathrm{R}^{2}=0,69\right)$ говорит о том, что оставшиеся в улучшенной модели факторы влияют на уровень рентабельности зерна на $69 \%$, а неучтенные в данной модели факторы всего на $21 \%$.

С целью оценки существенности влияния изучаемых факторов на уровень рентабельности зерна построим многофакторный дисперсионный комплекс. 
Таблица 4

Дисперсионный анализ.

\begin{tabular}{|l|r|r|c|c|c|}
\hline & $d f$ & \multicolumn{1}{|r|}{$S S$} & $M S$ & $F$ & значимость $F$ \\
\hline Регрессия & 3 & 11225.99 & 3741.995 & 12.35555 & 0.000155846 \\
\hline Остаток & 17 & 5148.61 & 302.8594 & & \\
\hline Итого & 20 & 16374.59 & & & \\
\hline
\end{tabular}

Так как фактическое значение критерия Фишера $\mathrm{F}_{\text {факт }}=12.4$ значительно превосходит теоретическое значение критерия Фишера $F_{\text {теор }}=2,96$, то влияние заложенных в модель факторов на рентабельность зерна существенно.

Разработанная многофакторная корреляционно-регрессионная модель достаточно полно отражает условия производства зерна в исследуемой совокупности предприятий, а поэтому может быть использована для оценки результатов их деятельности и в частности для расчета резервов повышения уровня рентабельности зерна и увеличения денежной выручки за реализованное зерно.

Таблица 5

Резервы роста среднего уровня рентабельности зерна

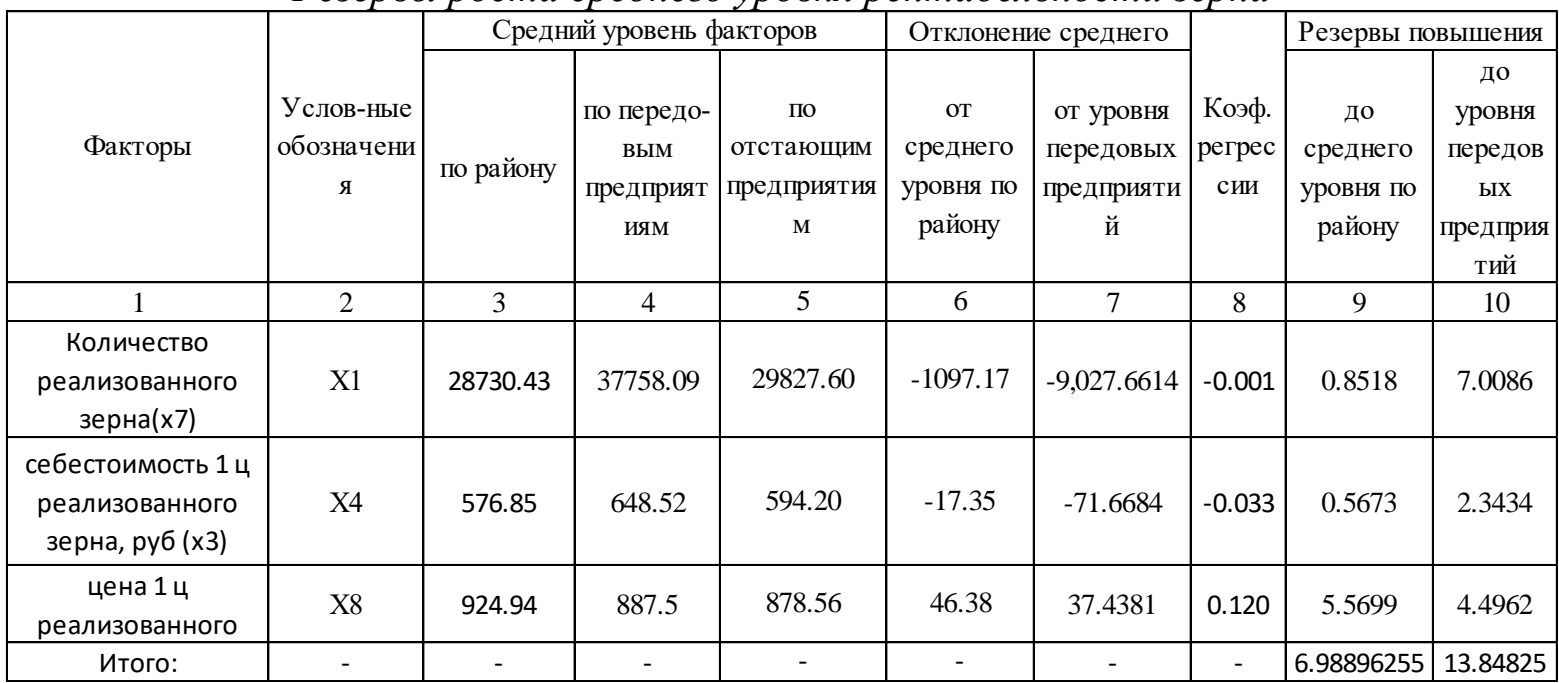

Анализируя данные таблицы 5, мы видим, что при достижении отстающих предприятий уровня средних уровень рентабельности при производстве зерна вырос на $6.9 \%$, а при достижении уровня производства передовых хозяйств уровень рентабельности повысился на $13.84 \%$.

Чтобы добиться планируемых результатов, следует в каждом отстающем хозяйстве определять внутренние ресурсы увеличения рентабельности и использовать их.

Для освоения выявленных резервов в исследуемых предприятиях необходимо:

1. Для повышения цены 1 ц. реализованного зерна можно использовать следующее:

a) минимизация сроков реализации единицы продукции;

б) увеличения спрос на продукцию;

в) улучшение качества зерновых;

г) прогнозирование инфляционных ожиданий.

2. Для увеличения количества 1 ц. реализованного зерна:

a) применение современного оборудования;

б) увеличение объемов производства;

в) недопущение потерь и порчи зерна. 
3. Для снижения себестоимости 1 ц. реализованного зерна:

a) поиск наиболее эффективных путей реализации продукции зерновых;

б) автоматизация производства;

в) расширение производства;

г) увеличение уровня организации труда.

$* * *$

1. Статистика : практикум для обучающихся (уровень бакалавриата) экономического факультета по направлениям 38.03.01 "Экономика" и 38.03.02 "Менеджмент" заочной формы обучения / [Н. В. Санина и др.] ; Воронежский государственный аграрный университет .- Воронеж : Воронежский государственный аграрный университет, 2018 .- 154 с.

2. Анализ затрат на производство продукции животноводства на основе применения индексного метода анализа. Ходилина М.П., Хаустова Г.И. В сборнике: Управление инновационным развитием агропродовольственных систем на национальном и региональном уровнях. Материалы международной научно-практической конференции. В 2-х частях. Ответственные за выпуск: Е.В. Закшевская, Т.В. Сабетова. 2019. С. 176-179.

3. Современные проблемы анализа затрат на производство продукции сельскохозяйственной организации. Селютина Т.В., Панина Е.Б. В сборнике: Актуальные проблемы и перспективы развития аудита, бухгалтерского учета, экономического анализа и налогообложения. Материалы национальной (всероссийской) научно-практической и методической конференции . 2019. С. $320-323$.

4. Анализ себестоимости продукции и определение резервов ее снижения. Афанасьева М.А., Панина Е.Б. В сборнике: Молодежный вектор развития аграрной науки. Материалы 67-й научной студенческой конференции. 2016. С. 13-18.

5. Анализ взаимосвязи производства и потребления продукции животноводства по Воронежской области. Степанова Т.А., Ануфриева А.В. В сборнике: Актуальные вопросы устойчивого развития АПК сельских территории. Материалы Всероссийской научно-практической конференции, посвященной 50-летию со дня образования кафедры экономического анализа, статистики и прикладной математики. 2018. С. 49-52.

\section{Султонова Н.И. \\ Микрофинансирование как фактор развития бизнеса}

(Узбекистан, Ташкент)

doi: $10.18411 / \mathrm{j}-07-2021-50$

\section{Аннотация}

В данной статье анализируется текущая ситуация в Узбекистане в международном рейтинге «Doing Business» и исследуется кредитная деятельность микрокредитных организаций и коммерческих банков в стране, которая имеет прямое влияние на данный показатель.

Ключевые слова: кредит, «Получение кредита», международный рейтинг
«Doing Business», микрокредитование, микрокредитные организации,
предпринимательство.

\section{Abstract}

This article analyzes the current situation in Uzbekistan in the international ranking of "Doing Business" and examines the lending activities of microcredit organizations and commercial banks in the country, which have a direct impact on this indicator.

Keywords: credit, "Getting a loan", "Doing business" international rating, microcredit, microcredit organizations, entrepreneurship.

\section{Введение}

Микрофинансирование играет важную роль в решении социальных проблем государства, поскольку предоставление финансовых услуг населению и бизнесу 